\title{
Using the Honours Project Course to Enhance Engagement ACross All Stakeholders
}

\author{
Zebb Prime, Will Robertson, Ben Cazzolato, Dorothy Missingham, \& Colin Kestell \\ School of Mechanical Engineering \\ The University of Adelaide \\ Adelaide, \\ Corresponding Author: dorothy.missingham@adelaide.edu.au
}

\begin{abstract}
Prior to 2009 students in the School of Mechanical Engineering at the University of Adelaide developed their management and professional practice skills in an unpopular stand-alone course "Engineering Management and Professional Practice (EMPP)". The intended learning outcomes of this course were, however, synergistic with those of the final year "Honours Project" and so the two courses were strategically combined. This amalgamation (which is still referred to as the "Honours Project") has developed into a successful scaffolded, authentic, engineering problem based learning course that: motivates and engages over 200 participating students; effectively outreaches to both primary and secondary schools; attracts vibrant and enthusiastic industry interaction; draws significant news and media coverage as the University showcases and creates a nexus between the research and the professional communities. It represents the coordinated sustained efforts by a team of over 50 academic and professional staff within the School of Mechanical Engineering, the Faculty of Engineering Computer and Mathematical Sciences and the University administrative services; which include the Media and Strategic Communications office, and the offices of the Vice Chancellor (VC) and the Deputy Vice ChancellorAcademic (DVCA). This paper discusses the background and evolution of the integrated Honours Project (Mech. Eng. 4143). Importantly, responses of key stakeholders, to the course work and outcomes are examined. These stakeholders include current students, industry, community members and academics. Suggestions for continued evolution and improvements will also be discussed.
\end{abstract}

Keywords: integrated PBL and management; professional practice; stakeholders; engagement; capstone project.

\section{INTRODUCTION}

\subsection{Background}

The Honours Project in the School of Mechanical Engineering at The University of Adelaide is now the most significant part of the final year in all of the School's five degree programs. It homogeneously amalgamates the technical, communication and team skills of the students in an a learning environment linked to authentic engineering problems. The Honours Project spans two semesters and accounts for nine out of a total of either 21 or 24 course units (depending on individual degree or double degree structure) across one year. Students form small groups (of up to ten students), receiving individual supervision and close mentorship by academic staff and workshop staff, while they work on their topic of investigation that was chosen prior to the beginning of the academic year. Chosen projects range from design and build to theoretical research topics, and many projects are often cross-disciplinary, open-ended and industry sponsored. In addition to the project, the course also comprises structured workshops and a series of support lectures covering areas such as project and risk management, human resources, project finance and engineering law.

Coursework assessment is broken into two main components: project assessment (67\%) and management and professional practice assessment (33\%). In addition to the tangible research and design solutions, the project also requires: a project charter in which the students themselves define the scope of their project and the measureable goals (which they are assessed against at the end of the year); a preliminary report mid-year; a professional conference style seminar presentation (within two parallel sessions over three days open to the public); a final report and most notably a public exhibition called "MechExpo", at which students must present, demonstrate and explain their work to a broad, public audience.

In many cases, students will also prepare a conference or journal publication based on their research during the year. The workshops and lectures (once part of EMPP) are presented by professional industry leaders, lawyers and accountants, with a curriculum that scaffolds the professional practice elements of the authentic problem based learning project. This revised combined approach has led to significant improvements to the learning outcomes and student engagement for both the Honours Project as well as embracing management practices. 


\section{ENGAGEMENT}

\subsection{Literature}

Final year, or capstone, projects in engineering degree progams are common in higher education institutions in many countries. The importance that these projects play in both preparing students for industry, and preparing students for research careers is recognised by professional and accreditation bodies alike. Nationally, Engineers Australia (EA), lists the "Application of established engineering methods to complex engineering problem solving" [1] as a key professional expectation of the Stage One Competency Standards (nd), while the Australian Qualifications Framework (AQF) [2] list expectations of students " to plan and execute project work and/or a piece of research and scholarship with some independence". These expectations are in keeping with with those of the Canadian Engineering Accreditation Board (CEAB), Accreditation Board for Engineering and Technology (ABET), and the large trans-national European Accreditation of Engineering (EUR-ACE) organization which states that graduates "should be able to use appropriate methods to pursue research or other detailed investigations of technical issues" and that these investigations "may involve literature searches, the design and execution of experiments, the interpretation of data, and computer simulation." [3]

However, the approach taken and the requirements of the capstone project in engineering can vary greatly between different $\mathrm{HE}$ institutions. For example, in contrast to the Honours Project presented here, which comprises $38 \%$ to $43 \%$ of the final year of study, in Quebec Province only 12\% of the final year of study is required for the capstone project [4] . At Stevens Institute of Technology [5] in New Jersey, New York, courses in engineering professional practice are linked to the capstone design project. This linking is somewhat similar to the Adelaide approach, but varies in the nature of the underlying philosophy; the Stevens program uses EMPP modules developed by the American Society of Mechanical Engineers, whereas Adelaide has developed a 'bespoke' curriculum approach.

This paper presents a short case study of the integrated, level four Honours Project course (Mech. Eng.4143), in the School of Mechanical Engineering The motivation behind this case study is to discuss the evolution of the course with particular emphasis on increasing student engagement in all aspects of the learning, as well on the leadership structure that is in place to support the learning. A brief overview of responses of key stakeholders, including students, industry and community members, and academics is also provided. It is intended that this examination will serve as the basis for developing a more intensive longitudinal study.
In a typical year, approximately 200 students across 65 projects will undertake the Honours Project, in which the School invests over $\$ 1,000,000$ p.a. in its delivery; including a $40 \mathrm{hr}$ per student electrical and mechanical workshop support allowance, plus a minimum budget of $\$ 200$ per student. Industry sponsorship and mentoring of students is strongly encouraged, with approximately one third of projects directly proposed by industry, research partners or NGOs. Yet, despite strong engagement in the project, student engagement in EMPP increased only after the amalgamation made clear the links to authentic engineering practice; in this case the showcasing of the project products and outcomes through the "MechExpo".

While engineering junior students, academics, industry advisors and the public at large all attend the students' (conference style) seminar presentations, it is the "MechExpo" that is the culmination of a year of project work. This highly attended event (held off-campus on $4000 \mathrm{~m}^{2}$ of the Adelaide Event \& Exhibition Centre) costs over $\$ 200 \mathrm{k}(>\$ 100 \mathrm{k}$ cap. ex.) to stage, but offers tremendous value for money in terms of the educational experience as well as engagement with schools across the state, industry, sponsors, the research community and public at large, via direct attendance and through television news and features on children's science programs. The schematic below (Figure 1) shows the variety of groups or stakeholders engaged in the School of Mechanical Engineering, Honours Project "MechExpo".

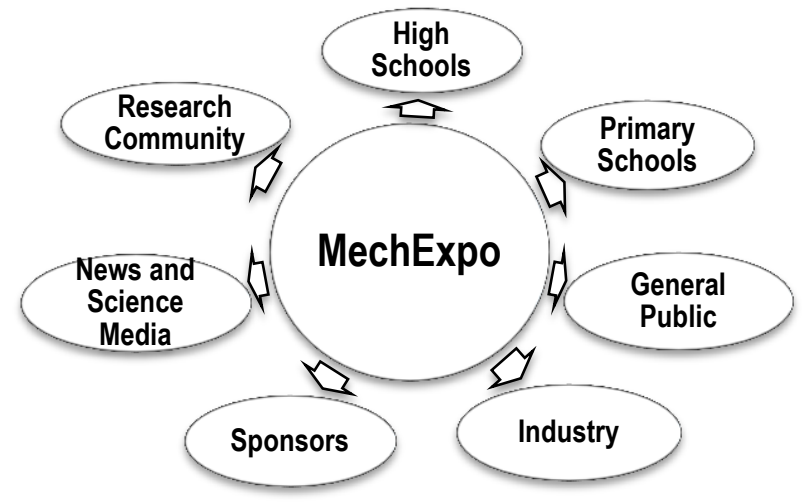

Figure 1: The variety of stakeholder engagement with the "MechExpo"

Such engagement has led to significant beneficial outcomes for all stakeholders, well beyond the immediate financial support and mentorship; for the Honours Project students themselves these have included employment, patents and research linkages. 
The two day public event of MechExpo includes professional level booths of students' exhibits, electronic multi-media, hands-on displays and poster displays. The student teams and projects are assessed by a panel of 30 industry judges. The ECMS Faculty Outreach officers provide information sessions for the $600+$ primary and secondary school students and their teachers in attendance. MechExpo is undoubtedly the School's flagship event, providing a mechanism by which current students can demonstrate to the broader community their skills and to promote science, technology, mathematics and engineering.

\section{LEADERSHIP}

The immense scale of the collective components of the Honours Project, requires a cohesive central team to ensure the quality of educational outcomes and the smooth running of the events and meeting deadlines. Figure 2 shows the outline of the leadership team that includes the overall Coordinator, whose complex role ensures the smooth running the full year of Honours Project. The Project Events and Resource Coordinator organises the project events and resource requirements, which also involves coordinating a small army of helpers around the time of both the Seminar Presentations and MechExpo. The EMPP Lecturer and Tutor Coordinator coordinates the learning and teaching aspects of the EMPP course, as well as coordinating the industry expert lecturers, and the tutors who assist in the workshops and assignment exercises. The Curriculum Advisor and Liason member of the central team has helped to evolve the curricula of the course, working closely with the Honours Project coordinator to ensure that the students are engaged in an holistic learning experience that brings together their technical knowledge and professional practice skills.

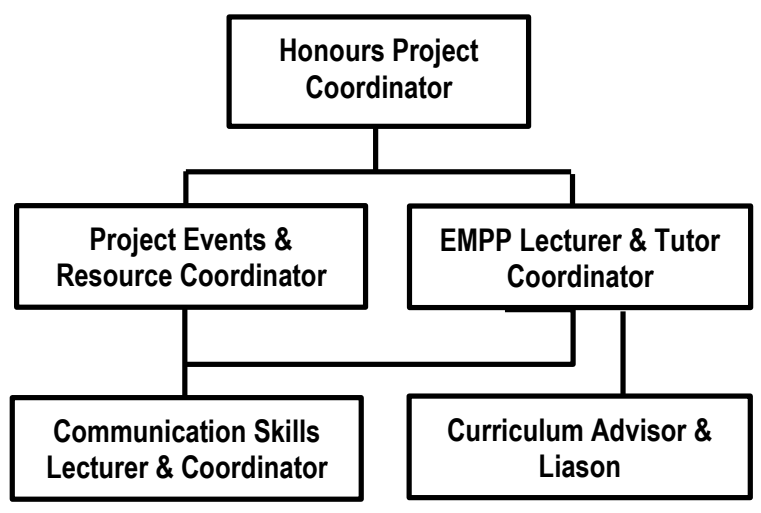

Figure 2: The leadership structure of the combined Honours Project and EMPP course.
Communication is an overarching issue, in terms of seminar presentations, poster presentation, exhibitions and most notably the final written report (thesis). The Communication Skills Coordinator works closely with all of the teams throughout the year on these issues to help ensure an excellent quality of communication from all students. An additional dimension of the communication framework is provided by exposing the junior undergraduates to the Honours Project, which motivates their learning with an exciting objective for final year. Formal integration of learning as part of a "spiral curriculum" [6] approach has also been introduced to Mechanical Engineering students. For example, students in both level 1 and level 3 design and communication courses, across all five degree programs, are tasked with completing assessments based around attendance at and analysis of the Honours level Seminars.

\section{RESULTS}

Amalgamating EMPP with the Honours Project, as well as the evolved scale of the combined course, has produced significant positive results in terms of student experience, engagement and outreach. Prior to 2009 the student evaluations of EMPP were (without understatement) terrible. One student (typical of many) commented "I cannot see the point of this course when I want to be an engineer. How is this relevant to me". At its lowest point, there was less than $40 \%$ broad agreement that "overall I am satisfied with the quality of this course". In contrast the project had an $86 \%$ broad agreement. However two years later (in 2011) 91\% of students expressed that they were satisfied with the amalgamated evolution of the Honours Project. Written responses included: "This project is great! It finally made me start to feel like a real engineer"; "The financial lectures really helped with our budgeting and cost control"; "Applying engineering skills to something real in a great team"; "Spending time with my supervisor really helped provide the confidence I needed"; "The exposure to industry was fantastic, I secured an interview!'.

Additionally, in a typical year the Honours Project leads to 6-12 journal papers and 10-20 conference papers, presented at both national and international conferences. Many of these papers have won student prizes and some the best overall paper.

In 2013 approximately 2000 people attended the MechExpo, almost half of whom were school students. Typical comments from school students include "I didn't know engineers did such cool things." (Kendall, aged 13) and "...every year I ask my parents to go to MechExpo, even when my School does not go.” (Sarina, aged 16). Industry judges from previous years have again asked to take part in MechExpo for the current year. Dr Andrew Thomas (Australia's first astronaut) said that "I went to the [Mech]Expo to see these student projects and they 
were phenomenal. It's just mind blowing what these kids are doing." (see for example Figure 3, below).

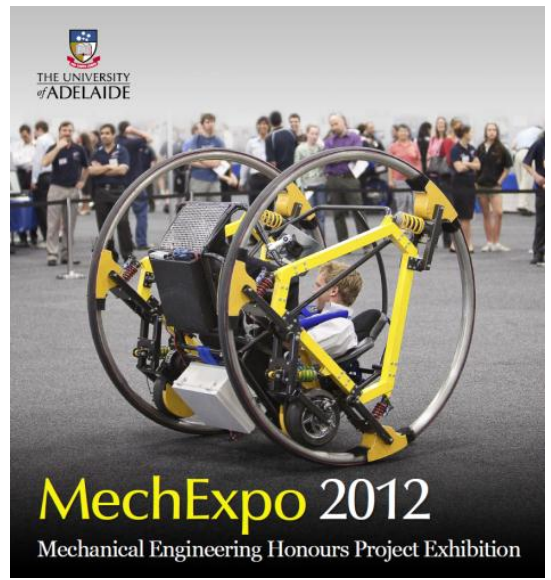

Figure 3: Poster for MechExpo 2012 showing a previous best project winner, being viewed in action by industry and community members.

Many engaging projects end up in print and electronic media, including Channel 7, 10 and ABC News; Scope TV, BTN, Totally Wild and the Discovery Channel, and are promoted through the MechExpo website. Honours Projects have featured on the cover of several international magazines including Matlab Magazine. One YouTube posting of the Honours Project has received over 800,000 views. The Honours Project Coordinator has delivered keynote talks on the Honours Projects for major national and international companies, including National Instruments and Mathworks. In addition to these speaking engagements, the Project Coordinator was invited to exhibit at Techfest 2012 in Bombay, India.

\section{CONCLUDING REFLECTIONS}

A responsive flexible approach to the needs of $4^{\text {th }}$ year students undertaking a demanding year-long Honours Project, in the School of Mechanical Engineering at the University of Adelaide, has resulted in its amalgamation with Engineering Management and Professional Practice. This amalgamation has both strengthened the Honours Project as well as engaging students more fully in the required professional practice learning thereby ensuring graduates are better prepared for the engineering industry. The recent restructuring together with the long running MechExpo has led to significant gains in industry and community involvement as well as promoting science, technology, engineering and mathematics to younger generations of students.

\section{References}

[1] Engineers Australia,. Stage 1 Competency Standard For Professional Engineer, n.d. Available as of August 182013 http://www.engineersaustralia.org.au/sites/default/files/shado/Ed ucation/Program\%20Accreditation/110318\%20Stage $\% 201 \% 20$ Professional $\% 20$ Engineer.pdf.

[2] Australian Qualifications Framework 2013. Avalable as of https://www.google.com.au/search?q=AQF\&hl=en

[3] European Network for Accreditation of Engineering Education, 2008 EUR-ACE Framework Standards for the Accreditation of Engineering Programmes, available: http://www.enaee.eu/wp-content/uploads/2012/01/EURACE_Framework-Standards_2008-11-0511.pdf, retrieved: January 222014

[4] Mick Healey, Laura Lannin, Arran Stribe and James Deounian, Developing and enhancing undergraduate final-year projects and dissertations, Glouchester, The Higher Education Academy, July 2013. Available as of October 2013 from http://scholar.google.com.au.proxy.library.adelaide.edu.au/schol ar?as_ylo=2013\&q=Developing+and+Enhancing ++ Healey \&hl= en\&as_sdt=0,5

[5] Gonca Altuger-Genc and Constantin Chassapis, "Fostering Lifelong Learning in a Capstone Design Environment: An Implementation Assessment", Frontiers in Education Conference (Rapid City SD; 12-15 Oct 2011) 2011. Available as of February 23, 2014 from

http://ieeexplore.ieee.org.proxy.library.adelaide.edu.au/xpls/abs _all.jsp?arnumber $=6142883 \& \operatorname{tag}=1$

[6] Jerome, S. Bruner, The Process of Education, Cambridge MA, Harvard University Press, 1960( $1^{\text {st }}$ ed.), 97pp \{ISBN: 0674-71001-0\}. 